\title{
Retraction Note: Ellagic Acid Improves Testicular Dysfunction via Autophagy in a Tamoxifen-Injured Rat Model
}

\author{
Ali Olfati ${ }^{a}{ }^{* *}$ and Hassan Khamisabadi ${ }^{b}$ \\ ${ }^{a}$ Department of Animal Science, Faculty of Agriculture, University of Tabriz, Tabriz, Iran \\ ${ }^{b}$ Animal Science Department, Kermanshah Agricultural and Natural Resources Research and \\ Education Center, Agricultural Research, Education and Extension Organization (AREEO), \\ Kermanshah, Iran \\ *e-mail: A.Olfati65@gmail.com
}

DOI: $10.1134 / \mathrm{S} 0022093020060113$

The editor-in-chief of Journal of Evolutionary Biochemistry and Physiology has retracted this article [1], because the study has not been carried out at University of Tabriz as it was indicated in the article, and therefore the approval of the techniques by the Ethics Review Committee of Tabriz University, Iran, could not be obtained. Ali Olfati agreed with this decision and Hassan Khamisabadi has not replied to any letters from the editor.

\section{REFERENCES}

1. Olfati, A. and Khamisabadi, H., Ellagic Acid Improves Testicular Dysfunction via Autophagy in a Tamoxifen-Injured Rat Model, Journal of Evolutionary Biochemistry and Physiology, 2020, vol. 56, pp. 265-276. https://doi.org/10.1134/ S0022093020030096 